Article

\title{
Crocus sativus L. Extract Containing Polyphenols Modulates Oxidative Stress and Inflammatory Response against Anti-Tuberculosis Drugs-Induced Liver Injury
}

\author{
Adil Farooq Wali ${ }^{1, *} \oplus$, Jayachithra Ramakrishna Pillai ${ }^{1} @$, Yusra Al Dhaheri ${ }^{2}$, \\ Muneeb U. Rehman ${ }^{3, *}$, Ambreen Shoaib ${ }^{4}$ D, Omar Sarheed ${ }^{1}$, Salma Jabnoun ${ }^{1}$, \\ Maryam Razmpoor ${ }^{1}$, Saiema Rasool ${ }^{5}$, Bilal Ahmad Paray ${ }^{6}$ and Parvaiz Ahmad ${ }^{7,8}$ (D) \\ 1 Department of Pharmaceutical Chemistry, RAKCOPS, RAK Medical and Health Sciences University, \\ Ras Al Khaimah 11172, UAE; jayachithra@rakmhsu.ac.ae (J.R.P.); sarheed@rakmhsu.ac.ae (O.S.); \\ Salma.17903015@rakmhsu.ac.ae (S.J.); Maryam.17903010@rakmhsu.ac.ae (M.R.) \\ 2 Department of Biology, College of Science, United Arab Emirates University, Al Ain 15551, UAE; \\ yusra.aldhaheri@uaeu.ac.ae \\ 3 Department of Clinical Pharmacy, College of Pharmacy, King Saudi University, Riyadh 11451, Saudi Arabia \\ 4 Department of Pharmacology, Faculty of Pharmacy, Integral University, Lucknow 226026, India; \\ amber8739@yahoo.com \\ 5 Forest Biotechnology Lab, Department of Forest Research Management, Faculty of Forestry, University of \\ Putra, Serdang, Selangor 43400, Malaysia; saimu083@gmail.com \\ 6 Zoology Department, College of Science, King Saudi University, Riyadh 11451, Saudi Arabia; \\ bilalcare@gmail.com \\ 7 Botany and Microbiology Department, College of Science, King Saudi University, Riyadh 11451, \\ Saudi Arabia; parvaizbot@yahoo.com \\ 8 Department of Botany, S.P. College, Srinagar, Jammu and Kashmir 190001, India \\ * Correspondence: farooq@rakmhsu.ac.ae (A.F.W.); muneebjh@gmail.com (M.U.R.)
}

Received: 22 December 2019; Accepted: 17 January 2020; Published: 30 January 2020

\begin{abstract}
The purpose of this study is to analyze the polyphenolic rich extract of Crocus sativus L. petals (CSP) in modulating liver oxidative stress and inflammatory response status against rifampicin isoniazid (INH-RIF) drug-induced liver injury. The INH-RIF was administered for 14 days with varying doses in Wistar rats, while silymarin was administered as standard dose. We report the defensive impacts of CSP against INH-RIF induced liver oxidative stress and proinflammatory cytokine. The CSP treatment at both doses significantly controlled all modulating biochemical hepatic injury indicators and resulted in the attenuation of arbitral INH-RIF damage. The components present in CSP identified by LC-ESI-Q-TOF-MS were found to be flavonoids and fatty acids. It can be inferred that CSP possesses a hepatoprotective capacity against INH-RIF-mediated hepatic injury, which may prove to be a medically beneficial natural product for the management of drug-induced liver injury.
\end{abstract}

Keywords: anti-tuberculosis; Crocus sativus; cytokines; hepato-toxicity; polyphenols; silymarin

\section{Introduction}

Tuberculosis (TB) has been one of the major communicable diseases in the world over the past two decades. Regardless of the development of various new diagnostic tools and medicines in the last 20 years, TB stays a worldwide emergency [1]. World Health Organization reported that in year 2017 around more than 10 million people became sick because of TB and approximately 3 million people die each year [2]. Different medications are used in the treatment of susceptible or mono-resistant 
tuberculosis such as isoniazid (INH), rifampicin (RIF), pyrazinamide (PZA), ethambutol (EMB), streptomycin, and durazinamide; however, the RIF and INH combinations act as a first-line treatment regimen for 4 to 6 months [3]. Literature survey reported various adverse reactions of antituberculosis (ATC) drugs. One of the adverse reaction of RIF and INH drugs is the development of drug-induced hepatotoxicity (DIH); independently and in combination DIH is amplified in a synergistic manner [4].

Natural products are one of the main source of drugs used by humans worldwide and are currently in huge demand within the context of health care provision and reform [5,6]. Across the globe, various plants are used as traditional medicines for the management of hepatic ailments, currently there are few allopathic medicines available on the market with hepatoprotective activity. Therefore, natural products may offer efficacious, alternative source for the treatment of hepatic disorders [7].

Crocus sativus L. (CS) also popularly known as saffron is a flowering plant belonging to the Iridaceae family and cultivated in countries such as Iran, Spain, Italy, etc., [8]. The chemical composition of the CS varies from region to region, seasonal diversification and flora origin [9]. CS contains various secondary metabolites that are responsible for different pharmacological activities. Traditionally CS has been used for various ailments like antihypertensive [10], neuroprotective [11], antitussive [12], aphrodisiac [13], antioxidant [14], antinociceptive [15], anti-inflammatory [16] activities.

Keeping in mind the above considerations, the purpose of the current study is to study the effect of C. sativus petals extract (CSP) on the liver oxidative stress and inflammatory response status against INH-RIF-induced liver injury.

\section{Results}

\subsection{Chemical Profiling of CSP by LC-ESI-Q-TOF-MS}

Polyphenolic rich extract was achieved by ultrasonic homogenizer extraction technique using $90 \%$ ethanol as a solvent as described. In the current study, the chemical profiling of CSP polyphenolic rich extract was carried out by means of by LC-ESI-Q-TOF-MS; the molecular mass (m/z) and lambda $\max (\lambda \max )$ of the chemical compounds were compared with various database, literature survey, and research articles shown in Table 1. According to the identification data, the chemical compounds identified in CSP polyphenolic rich extract were flavonoids mostly flavonol derivatives along with fatty acids derivatives as shown in Figure 1. The most dominating chemical compound present in the CSP extract was rutin.

Table 1. Chromatographic condition and characterization of chemical profiling of Crocus sativus L. petals (CSP) by LC-ESI-Q-TOF-MS.

\begin{tabular}{cccccc}
\hline Peak No. & $\begin{array}{c}\text { Retention Time } \\
(\mathbf{m i n})\end{array}$ & $\begin{array}{c}\text { Molecular } \\
\text { Formula }\end{array}$ & $\begin{array}{c}\text { Theoretical } \\
(\mathbf{m} / \mathbf{z})\end{array}$ & $\begin{array}{c}\text { Measured } \\
(\mathbf{m} / \mathbf{z})\end{array}$ & Compound Name \\
\hline 1 & 7.241 & $\mathrm{C}_{25} \mathrm{H}_{37} \mathrm{NO}_{5}$ & 431.2722 & 432.2796 & $\begin{array}{c}\text { Hydroxysalmeterol } \\
\text { Morin }\end{array}$ \\
2 & 7.417 & $\mathrm{C}_{15} \mathrm{H}_{10} \mathrm{O}_{7}$ & 302.0417 & 303.0490 & $\begin{array}{c}\text { Quercetin } \\
\text { Rutin }\end{array}$ \\
3 & 7.704 & $\mathrm{C}_{21} \mathrm{H}_{20} \mathrm{O}_{11}$ & 448.0995 & 449.1068 & 611.1595 \\
5 & 7.903 & $\mathrm{C}_{27} \mathrm{H}_{30} \mathrm{O}_{16}$ & 610.1523 & & $\begin{array}{c}\text { 1alpha,25-dihydroxy-26,27- } \\
\text { dimethyl-20,21,22,22,23,23 }\end{array}$ \\
5 & 8.107 & $\mathrm{C}_{30} \mathrm{H}_{44} \mathrm{O}_{3}$ & 452.335 & 454.3459 & $\begin{array}{c}\text { Fisetin } \\
\text {-hexadehydro-24ahomovitaminD3 }\end{array}$ \\
7 & 8.499 & $\mathrm{C}_{15} \mathrm{H}_{10} \mathrm{O}_{6}$ & 286.047 & 287.0543 & $\begin{array}{c}\text { Methyl jasmonate } \\
6\end{array}$ \\
8 & 12.887 & $\mathrm{C}_{13} \mathrm{H}_{20} \mathrm{O}_{3}$ & 224.1408 & 225.1481 & $\begin{array}{c}\text { 10-Hydroxy-8E-Decene-2,4,6- } \\
\text { triynoic acid }\end{array}$ \\
9 & 13.477 & $\mathrm{C}_{10} \mathrm{H}_{8} \mathrm{O}_{3}$ & 176.0473 & 177.0546 & $\begin{array}{c}\text { Methyl 8-[2-(2-formyl-vinyl)-3- } \\
\text { hydroxy-5-oxo-cyclopentyl] } \\
\text {-octanoate } \\
\text { Odecanamide }\end{array}$ \\
\hline
\end{tabular}



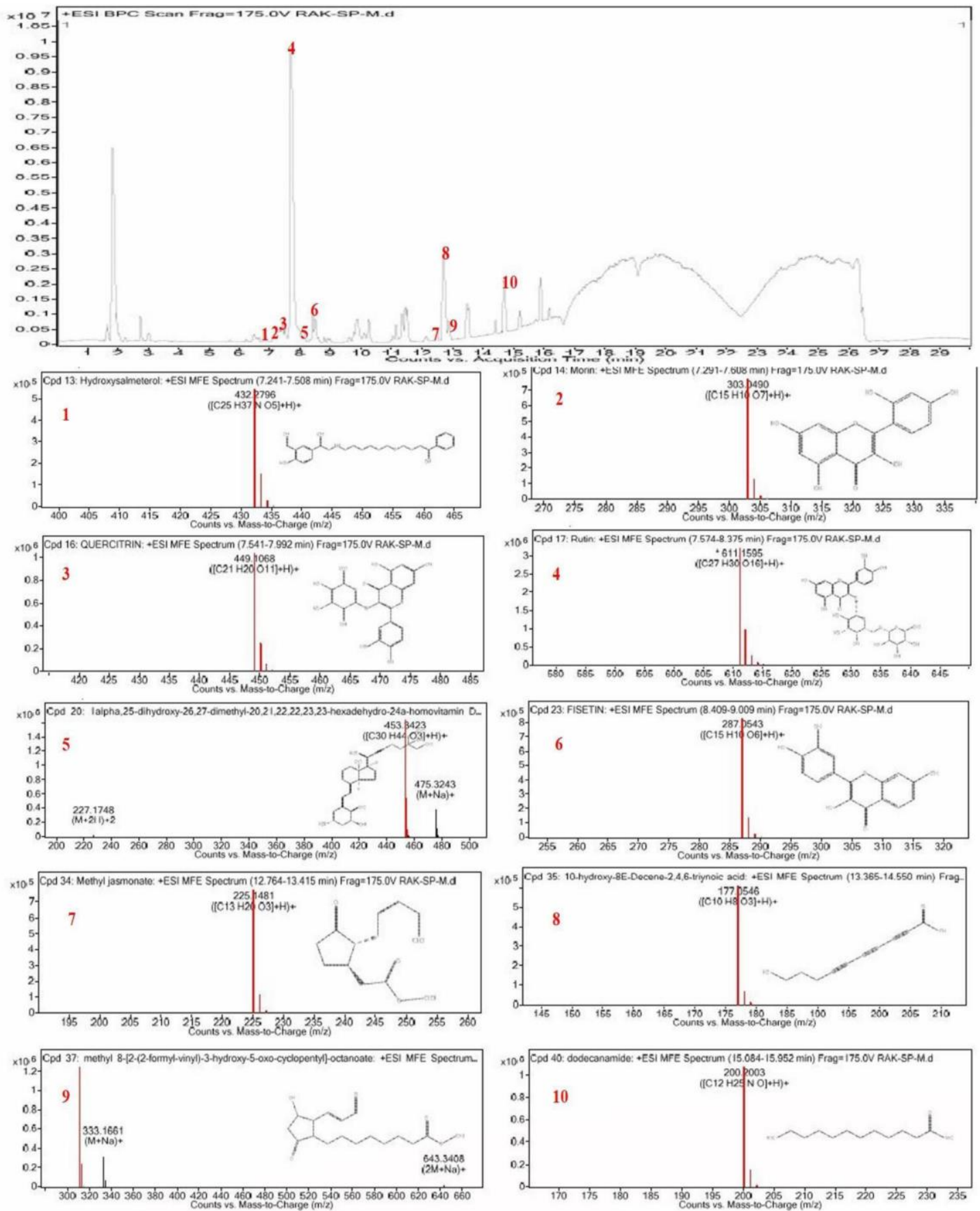

Figure 1. Representative full scan chromatographic profile of CSP and the extracted ion chromatograms.

\subsection{Estimation of TPC and TFC}

Total phenolic content of CSP estimated by calibration curve with $R^{2}=0.992$ was $89.63 \pm 0.99 \mathrm{mg} \mathrm{GAE} / \mathrm{g}$, whereas the total flavonoids content with $R^{2}=0.989$ was $65 \pm 1.09 \mu \mathrm{g} \mathrm{QE} / \mathrm{g}$ Table 2. 
Table 2. Total phenolic content and flavonoids content of CSP.

\begin{tabular}{ccc}
\hline Methods & CSP & R2 \\
\hline Total phenolic content $(\mathrm{mg}$ GAEa/g of extract) & $89.63 \pm 0.99$ & 0.992 \\
\hline Total flavonoids content $(\mu \mathrm{g} \mathrm{QEb} / \mathrm{g}$ of extract) & $65 \pm 1.09$ & 0.989 \\
\hline
\end{tabular}

a Total phenolics content is expressed in terms of gallic acid equivalent ( $\mu \mathrm{g}$ of GAE/g); ${ }^{\mathrm{b}}$ Total flavonoids content is expressed in terms of quercetin equivalent $(\mu \mathrm{g}$ of $\mathrm{QE} / \mathrm{g})$. Values are expressed as mean \pm standard deviation $(n=3)$.

\subsection{In Vitro Antioxidant Activity}

The $\mathrm{IC}_{50}$ value of DPPH and ABTS assays were $99.53 \pm 0.63$ with $R^{2}=0.992$ and $116.63 \pm 1.93$ with $R^{2}=0.990$ of CSP at a concentration of $150 \mu \mathrm{g} / \mathrm{mL}$ respectively. The results were related with butylated hydroxyanisole as standard sample, which shows an $\mathrm{IC}_{50}$ value of $65.46 \pm 1.22$ with $R^{2}=0.901$ Table 3 .

Table 3. Antioxidant activity of CSP.

\begin{tabular}{ccccc}
\hline & CSP IC $_{\mathbf{5 0}}(\mu \mathrm{g} / \mathrm{mL})$ & $\boldsymbol{R}^{\mathbf{2}}$ & BHA IC $_{\mathbf{5 0}}(\mu \mathrm{g} / \mathrm{mL})$ & $\boldsymbol{R}^{\mathbf{2}}$ \\
\hline DPPH Assay & $99.53 \pm 0.63$ & 0.992 & $65.46 \pm 1.22$ & 0.901 \\
\hline ABTS Assay & $116.63 \pm 1.93$ & 0.990 & $87.42 \pm 0.990$ & 0.989 \\
\hline
\end{tabular}

All values are expressed as mean \pm standard deviation $(n=3)$.

\subsection{Elemental Analysis of the CS Petals Using ICP OES}

The results of the elemental analysis by ICP OES revealed the presence of 25 micro and macro elements in the CSP. The CSP was found to be very rich in potassium followed by calcium, phosphorous, magnesium respectively as shown in Table 4.

Table 4. Concentration of elements in CSP using inductively coupled plasma-optical emission spectrometry (ICP OES).

\begin{tabular}{lcc}
\hline S. No & Name of the Element & Concentration $(\mathbf{m g} / \mathbf{K g})$ \\
\hline 1. & Silver & 0.2 \\
\hline 2. & Aluminum & 555 \\
\hline 3. & Arsenic & 0.2 \\
\hline 4. & Boron & 17.2 \\
\hline 5. & Barium & 3.9 \\
\hline 6. & Beryllium & $<0.1$ \\
\hline 7. & Calcium & 4584 \\
\hline 8. & Cadmium & $<0.1$ \\
\hline 9. & Cobalt & 0.2 \\
\hline 10. & Chromium & 1.6 \\
\hline 11. & Copper & 9.6 \\
\hline 12. & Iron & 1192 \\
\hline 13. & Potassium & 22,256 \\
\hline 14. & Magnesium & 1751 \\
\hline 15. & Manganese & 33.9 \\
\hline 16. & Molybdenum & 0.6 \\
\hline 17. & Sodium & 211 \\
\hline & &
\end{tabular}


Table 4. Cont.

\begin{tabular}{lcc}
\hline S. No & Name of the Element & Concentration $(\mathbf{m g} / \mathbf{K g})$ \\
\hline 18. & Nickel & 3.4 \\
\hline 19. & Phosphorous & 3569 \\
\hline 20. & Lead & 0.7 \\
\hline 21. & Tin & 0.1 \\
\hline 22. & Selenium & 0.1 \\
\hline 23. & Strontium & 9.1 \\
\hline 24. & Vanadium & 1.2 \\
\hline 25. & Zinc & 60.2 \\
\hline
\end{tabular}

\subsection{Biochemical Analysis}

The findings showed that administration of INH-RIF combination in rats showed a significant increase in the hepatic biomarker concentrations of ALT $(p<0.05)$, AST $(p<0.001)$, and ALP $(p<0.01)$ in rats and a decrease in TP $(p<0.05)$ in rats compared to control group Table 5.

Table 5. Effects of the CSP on hepatic enzyme markers.

\begin{tabular}{ccccc}
\hline Groups & ALT $\left(\right.$ IUL $\left.^{-1}\right)$ & AST $\left(\right.$ IUL $\left.^{-1}\right)$ & ALP $\left(\right.$ IUL $\left.^{-1}\right)$ & TP $(\mathrm{g} / \mathbf{d L})$ \\
\hline Group I & $62.23 \pm 5.32$ & $87.21 \pm 5.23$ & $100.43 \pm 5.98$ & $9.34 \pm 0.21$ \\
\hline Group II & $143.90 \pm 3.54^{* * *}$ & $302.43 \pm 4.32^{* * *}$ & $278.21 \pm 3.65^{* * *}$ & $3.18 \pm 0.53^{* * *}$ \\
\hline Group III & $90.98 \pm 2.98^{\# \# \#}$ & $95.01 \pm 8.93^{\# \# \#}$ & $138.32 \pm 2.43^{\# \# \#}$ & $7.02 \pm 0.39^{\# \# \#}$ \\
\hline Group IV & $132.76 \pm 4.34^{\# \#}$ & $289.83 \pm 8.93^{\#}$ & $193.43 \pm 3.64^{\# \#}$ & $3.98 \pm 0.53^{\#}$ \\
\hline Group V & $99.21 \pm 7.03^{\# \#}$ & $145.83 \pm 6.83^{\# \#}$ & $143.29 \pm 4.83^{\# \# \#}$ & $5.08 \pm 0.98^{\# \#}$ \\
\hline \multicolumn{4}{c}{ Annotation: ${ }^{* * *} p<0.001$ vs control, ${ }^{\#} p<0.05^{\# \#} p<0.01,{ }^{\# \#} p<0.001$ vs group II. }
\end{tabular}

Whereas rats administered with CSP at doses of $100 \mathrm{mg} / \mathrm{kg}, 200 \mathrm{mg} / \mathrm{kg}$ b.wt and silymarin at doses of $10 \mathrm{mg} / \mathrm{kg}$ b.wt demonstrated lower regulation of hepatic biomarkers (ALT, AST, and ALP) and higher regulation of TP levels showing hepatoprotective activity of CSP. There was statistically significant reduction of ALT, AST, and ALP levels in rats administrated with $200 \mathrm{mg} / \mathrm{kg}$ b.wt CSP as compared with the toxic group.

\subsection{Estimation of $C A T, S O D$, and $M D A$}

The oxidative stress efficiency of CSP was measured against hepatotoxicity-stressed INH-RIF. The findings showed that there was a statistically significant decrease in catalase (CAT) and superoxide dismutase (SOD) concentrations in the toxic group and an increase in malondialdehyde (MDA) concentrations compared to the control group.

The rats administrated with $100 \mathrm{mg} / \mathrm{kg}, 200 \mathrm{mg} / \mathrm{kg}$ b.wt, and silymarin at $10 \mathrm{mg} / \mathrm{kg} \mathrm{b.wt} \mathrm{of} \mathrm{CSP}$ prevented this induction and CAT, SOD, MDA levels were normalized to their control values. The CSP at the dose of $200 \mathrm{mg} / \mathrm{kg}$ b.wt displayed maximum hepatoprotective as shown in Figure 2. 
a)

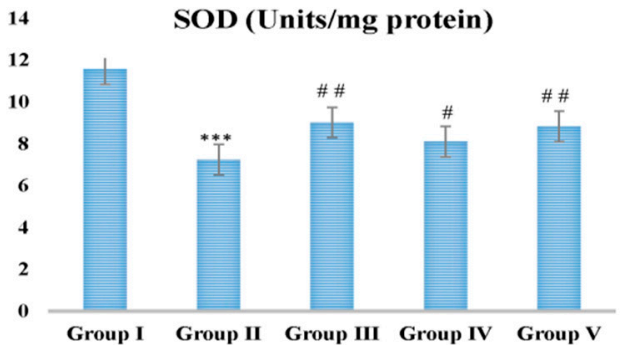

b)

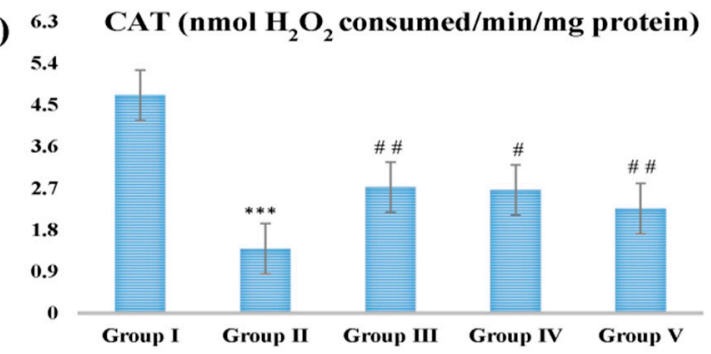

c) 25 MDA (mmol of MDA formed/g tissue)

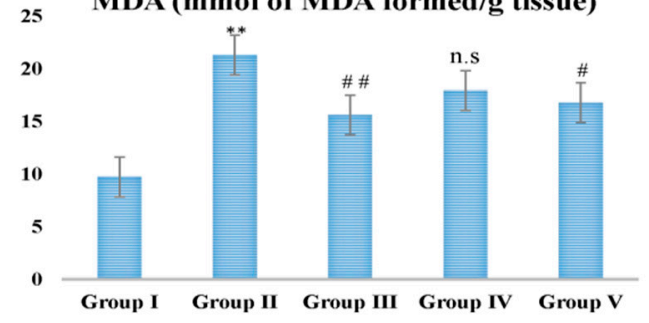

Figure 2. Effect of different doses of CSP and INH-RIF in vivo antioxidant enzymes (a) superoxide dismutase (SOD), (b) catalase (CAT), and (c) malondialdehyde (MDA). Values are mean \pm S.E.M; $n=6 ;{ }^{* *} p<0.01,{ }^{* * *} p<0.001$ vs. control, ${ }^{\#} p<0.05,{ }^{\# \#} p<0.01$ vs. group II, n.s stands for not statistically significant.

\subsection{Proinflammatory Cytokine Analysis}

The effect of CSP and INH-RIF treatment on (tumor necrosis factor alpha) TNF- $\alpha$ and cyclooxygenase-2 (COX-2) inflammatory mediators was analyzed. There was an increase in TNF- $\alpha$ and COX-2 levels in toxic group when compared with group I $(p<0.001)$. However, rats of group III, IV, and V administrated with CSP and silymarin showed decreased TNF- $\alpha$ and COX-2 levels significantly and dose dependently (Figure 3).
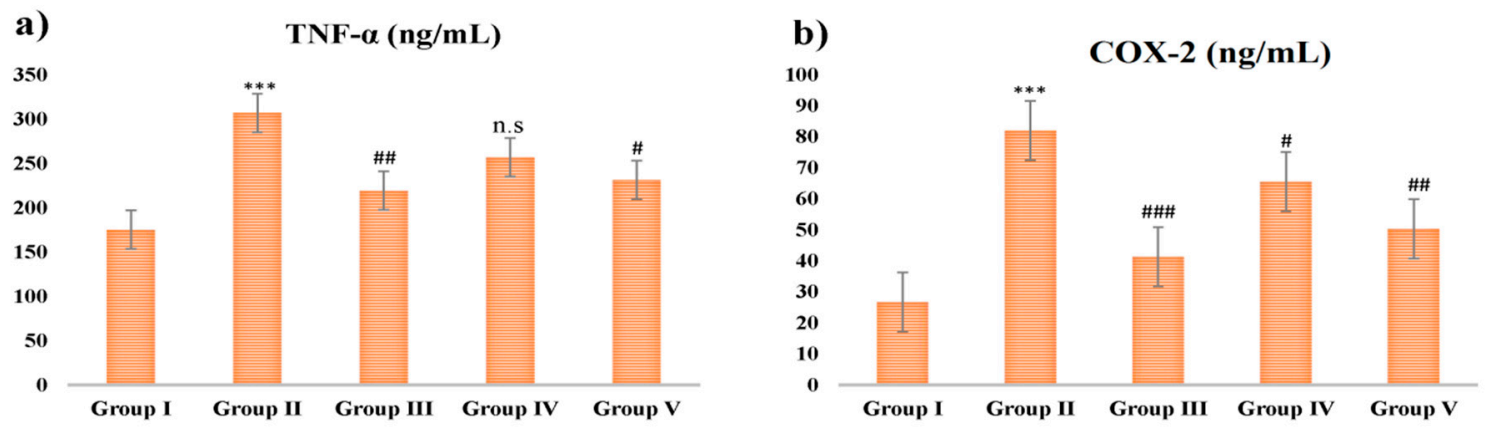

Figure 3. Effect of different doses of CSP on INH-RIF induced proinflammatory cytokines (a) TNF- $\alpha$ and (b) COX-2. INH-RIF showed steep rise in both the proinflammatory cytokines, administrated with CSP and silymarin decreased TNF- $\alpha$ and COX-2 levels significantly and dose dependently. Values are mean \pm S.E.M; $n=6$; ${ }^{* * *} p<0.001$ vs. control, ${ }^{\#} p<0.05,{ }^{\# \#} p<0.01,{ }^{\# \#} p<0.001$ vs. group II, n.s stands for not statistically significant.

\subsection{Histological Evaluation}

Histopathological studies have shown that there is a change in normal liver building design and apparent hepato-cellular necrosis and inflammation in group II compared to group I. Treatment with silymarin in group III prevented all histopathological anomalies caused by INH-RIF. Group III demonstrates highest regeneration of hepatocytes indicating its substantial hepatoprotective activity. Likewise, group $\mathrm{V}$ also had shown noticeable recovery, but recovery was lower compared to group III and much more noteworthy compared to group IV (Figure 4). 

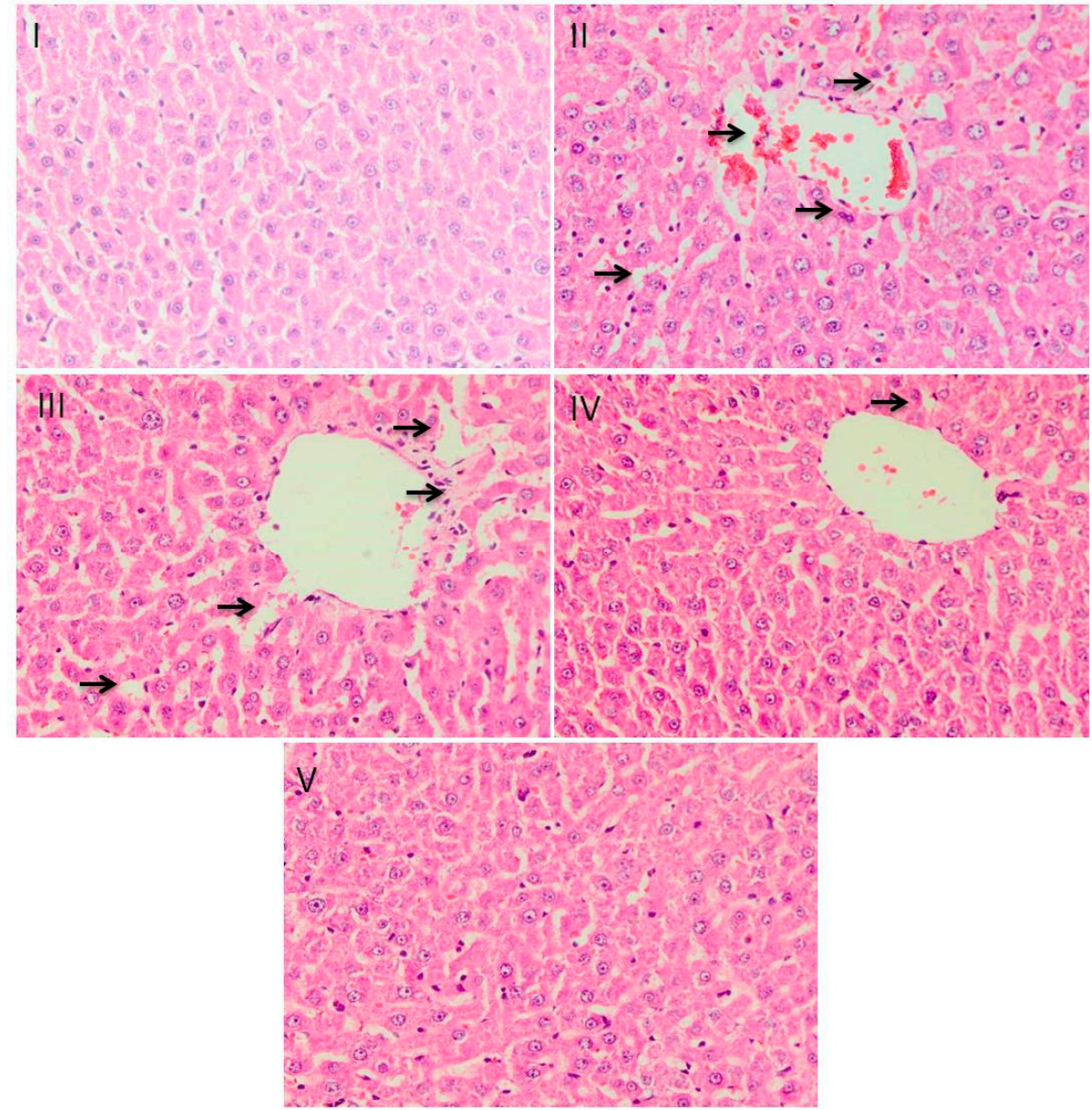

Figure 4. Effect of different doses of CSP on liver histoarchitecture in INH-RIF induced liver injury. Photomicrographs of staining of histological sections of colon depicting different experimental groups, group I exhibited the normal integrated cellular architecture. Group-II shows extensive disintegration of cells, which is the hallmark of INH-RIF toxicity. In groups III, IV and V CSP treatment showed protection against INH-RIF-induced histopathological damage. magnification: 40×.

\section{Discussion}

In the current study, we investigated the effects of CSP on the INH-RIF-induced liver injury in Wistar rats. The phytochemical screening of CSP by LC-ESI-Q-TOF-MS validated that the petals of CS are rich source of flavonoids [17]. Nine different bioactive chemical compounds were present in the CSP belonging mainly to flavonol, a derivative of flavonoids along with some fatty acid derivatives. Fisetin was the predominating component apart from morin, quercetin, and rutin present in this extract; all these compounds can negate the liver toxicity effect caused by INH-RIF via multiple mechanisms $[18,19]$. Recent studies have shown the health benefits of flavonoids and their potent antioxidant effects [20,21]. Flavonoid compounds are extremely important plant metabolites because of their free radical scavenging ability due to their hydroxyl groups. Therefore, the flavonoid content of plants may directly contribute specifically to their antioxidant and hepatoprotective activity [20-23]. Our results are compatible with the results of Bathaie and Mousavi [18], which showed that the $C$. sativus stigma possessed higher phenolic, flavonoid content and consequently higher antioxidant activity as compared to $C$. sativus petals [24]. The DPPH and ABTS assay are the most common method used to assess the radical scavenging ability of the different compounds because they have the capacity to give hydrogen free radicals. The mechanism behind the radical scavenging capacity is due to flavonoids and phenolic acids, and these are generally weak in nature, and thus act as competent electrons capable of responding to $\mathrm{O} 2 \mathrm{w}-$ depending on the substitution within the phenolic ring [25]. 
Our results are in line with previous literature that CSP was richest in essential and non-essential minerals which are necessary for human wellbeing [26,27]. INH-RIF was selected as a hepatotoxic because previously published studies have shown that INH-RIF induces significant changes in liver cell fortification processes, both enzymatic and non-enzymatic [28-30]. During the metabolism of INH by the liver, generation of acetylated metabolites like acetyl hydrazine and isonicotinic acid takes place which are responsible for hepato-cellular injury [31-34]. Whereas, during the metabolism of RIF, it gets converted to desacetyl rifampicin in liver which may lead to liver toxicity [34,35]. Previous reports suggested that, RIF when co-administrated with INH resulted in increased hepatic oxidative stress, and the synergistic effect of RIF and INH was assumed to be because of $\mathrm{CytP}_{-450}$ [36]. The above caused the rise in level of ALT, AST, and ALP due to leakage of enzymes from the liver and reduction in TP level in blood. It also changes the hepatocellular injury which includes hepatic cell augmentation, cholestasis, and alteration of endogenous antioxidants [35]. This study showed, rats treated with CSP at doses of $200 \mathrm{mg} / \mathrm{kg}$ b.wt and silymarin at $10 \mathrm{mg} / \mathrm{kg}$ b.wt have been shown to more efficiently restore ALT, AST, and ALP enzyme levels to normal. In comparison with our report, Omidi, et al. [36] reported that the C. sativus extract decreased the concentrations of hepatic enzyme markers in INH-RIF mediated liver toxicity. CSP exhibits hepatoprotective activity in accordance to the biological activity of flavonoid compounds in the erstwhile reports. Therefore, flavonoids like fisetin, morin, quercetin, and rutin chemical compounds are responsible for antioxidant and hepatoprotective activities of CSP $[20,22,23,37,38]$.

According to Bansal et al. [39] the endogenous antioxidant enzymes present in our body play as a defensive shield against the injury done by free radicals. The SOD enzyme whose purpose appears to reduce the harmful effects due to hydroxyl radical $\left({ }^{\circ} \mathrm{OH}^{-}\right)$by scavenges $\mathrm{O}^{-}{ }_{2}$ to $\mathrm{H}_{2} \mathrm{O}_{2}$ consequently, reduction of SOD level indicates hepatic injury. Similarly, CAT enzyme degrades $\mathrm{H}_{2} \mathrm{O}_{2}$ into water and oxygen to protect tissue from reactive oxygen species [40-43]. The risks of hepatotoxicity were raised because of an increase of free radicals and a lack of scavenging capacity of hepatocytes because of increased rates of antioxidant biomarkers [44]. Whereas, increase in the MDA level caused liver injuries because of oxidative stress $[45,46]$. Therefore, our results reveled that there is significant up regulation of SOD and CAT enzyme levels and decrease in the levels of MDA in the serum of animals. The results reveled hepato-protective activity of CSP at both doses.

The combination of INH-RIF metabolites stimulates Kuffer cells which cause activation of proinflammatory cytokines receptors such as TNF- $\alpha$ and COX-2, which are in turn involved in apoptosis and inflammation of the hepatocytes [47-51]. Our findings show that the concentrations of TNF- $\alpha$ and COX-2 in the INH-RIF-treated animals significantly increased as compared to the controlled animals. Nonetheless, following the administration of CSP and silymarin to INH-RIF-treated animals, the levels of TNF- $\alpha$ and COX-2 decreased significantly. Our results further proposed that hepatoprotective activity effects of CSP at 100 and $200 \mathrm{mg} / \mathrm{kg}$ b.wt were due to its potential to decrease the levels of both proinflammatory cytokines markers.

Histopathology has also shown that the treatment of CSP has provided significant immunity against hepatic damage. Metabolism of INH-RIF occurs largely in the liver, which is responsible for the susceptibility of the organ to metabolic-dependent, drug-induced damage [52]. These metabolites may be electrophilic compounds or free radicals that experience number of chemical reactions, like those of depletion of reduced glutathione; covalent linking to proteins, lipids, or nucleic acids; or causing lipid peroxidation [53]. CSP and its flavonoids demonstrated significant prophylactic impact as a result of antioxidant activity and is apparently seen in histological findings of liver sections with distinct hepatocytes, sinusoidal spaces, central veins, and mild degrees of fatty change, necrosis infiltration almost comparable to the group III group. These findings are in accordance with the earlier reports stating the role of flavonoids against hepatotoxicity and oxidative stress $[25,54]$. Previous studies have also established that flavonoids reverse INH-RIF-induced fibrosis and necrosis [55].

The hepatic biochemical markers, the endogenous antioxidant enzymes, proinflammatory cytokines markers the histological evaluation revealed that the CSP mostly at the dose of $200 \mathrm{mg} / \mathrm{kg}$ 
b.wt significantly attenuated the liver injury, which supports with the results of lower hepatic biochemical markers.

\section{Materials and Methods}

\subsection{Plant Material and Extraction}

C. sativus L. petals (CSP) were collected from Pampore $\left(34.02^{\circ}\right.$ N $74.93^{\circ}$ E.), south of Kashmir, India. After the collection, CS petals were dried in the shade and coarsely powdered. Then this coarse powder was transferred into a $500 \mathrm{~mL}$ reagent bottles (Borosil ${ }^{\circledR}$ ) and extracted with $90 \%$ ethanol using the ultrasonic homogenizer for $60 \mathrm{~min}$ at $35^{\circ} \mathrm{C}, 15 \mathrm{kHz}$ (BioLogics, Inc. 300VT). The extract was filtered with Whatman No. 1 filter paper (Supertex, grade 1), evaporated in vacuo (Buchi Rotavapor ${ }^{\circledR}$ R-210) and lyophilized using BenchTop Pro with Omnitronics ${ }^{\mathrm{TM}}$ freeze dryer. The CSP was then placed in the desiccator for further testing.

\subsection{Chemical Profiling of CSP by LC-ESI-Q-TOF-MS}

The phytochemical testing of plant polyphenols was carried out using an LC-MS instrument consisting of the Agilent 6200 series TOF/6500 series (Agilent ${ }^{\circledR}$ Technologies, Palo Alto, CA, USA) connected to the Agilent HPLC 1290 Infinity Binary Pump (Agilent ${ }^{\circledR}$ Technologies, Palo Alto, CA, USA) with an ESI interface. Zorbax Eclipse C18 column $(5 \mu \mathrm{m}, 150 \mathrm{~mm} \times 2.1 \mathrm{~mm})$ was used for chromatographic separation at a flow rate of $0.2 \mathrm{~mL} / \mathrm{min}$ with two separate mobile phases. Mobile phase (A) water and mobile phase (B) 90 per cent acetonitrile (0.1 per cent formic acid) with gradient system Table 6 . The temperature of the column was maintained at $40{ }^{\circ} \mathrm{C}$ and injection volume was $3 \mu \mathrm{L}$ with total run time of $30 \mathrm{~min}$. The LC-MS operating parameters are as follows: the spectra were obtained in ESI+ and ESI- modes in the range of $m / z=130-1000$, gas temperature $250^{\circ} \mathrm{C}$, gas flow $13 \mathrm{~L} / \mathrm{min}$, nebulizer $35 \mathrm{psig}$, sheath gas temperature $300{ }^{\circ} \mathrm{C}$, Sheath Gas Flow 11 capillary voltage $3.0 \mathrm{kV}$, and Fragmentor $125 \mathrm{~V}$. All spectral data were collected using a PDA detector. All information, acquisitions, and evaluation were regulated using the Agilent Mass Hunter Software version and the Agilent Database Library was used to verify the compounds.

Table 6. Chromatographic condition (gradient system).

\begin{tabular}{ccc}
\hline Time (min) & Function & Parameter \\
\hline 2.00 & Change Solvent Composition & Solvent composition A: $95.00 \%$ B: $5.00 \%$ \\
2.00 & Change Flow & Flow: $0.2 \mathrm{~mL} / \mathrm{min}$ \\
2.00 & Change Max. Pressure Limit & Max. Pressure Limit: 1200.00 bar \\
15.00 & Change Solvent Composition & Solvent composition A: $5.00 \%$ B: $95.00 \%$ \\
15.00 & Change Flow & Flow: $0.2 \mathrm{~mL} / \mathrm{min}$ \\
24.00 & Change Solvent Composition & Solvent composition A: $5.00 \%$ B: $95.00 \%$ \\
24.00 & Change Flow & Flow: $0.2 \mathrm{~mL} / \mathrm{min}$ \\
25.00 & Change Solvent Composition & Solvent composition A: $95.00 \%$ B: $5.00 \%$ \\
25.00 & Change Flow & Flow: $0.2 \mathrm{~mL} / \mathrm{min}$ \\
30.00 & Change Solvent Composition & Solvent composition A: $95.00 \%$ B: $5.00 \%$ \\
\hline
\end{tabular}

\subsection{Estimation of Total Phenolic Content (TPC)}

Folin-Ciocalteus assay was used to assess the total phenolic content of the CSP [51].

\subsection{Estimation Total Flavonoid Content (TFC)}

The colorimetric method was used to determine the total phenolic content of the CSP [56].

\subsection{In-Vitro Antioxidant Activity}

The antioxidant activity of CSP were determined by DPPH [24] and ABTS [57] assay. 


\subsection{Elemental Analysis of the CS Petals Using ICP OES}

Elements macro and micro were determined by using Spectro genesis ICP OES analyzer (SPECTRO Analytical Instruments, Germany). Calibration curves of standard solutions were used to evaluate each element.

\subsection{Induction of Hepatotoxicity in Wistar Rats}

Four to five-week-old male Wistar rats (165-190 gm) were used in the current study. All the experimental animals were kept under controlled environment and acclimatized for a week, fed $a d$ libitum food and water. The investigations were conducted as per the "Committee for the Purpose of Control and Supervision of Experiments on Animals Guidelines." Thirty male Wistar rats $(n=30)$ were included in the current study and are divided into five groups of six rats in each group. Group I animals were administrated $0.9 \%$ normal saline for 14 days p.o., therefore served as control group. Group II served as toxic group, animals were administrated only INH-RIF (1:1) $100 \mathrm{mg} / \mathrm{kg}$ b.wt for 14 days i.p. After one-hour of administration of INH-RIF (1:1) $100 \mathrm{mg} / \mathrm{kg}$ to the animals of groups III, IV, and V, groups IV and V animals were administered with $100 \mathrm{mg} / \mathrm{kg}$ and $200 \mathrm{mg} / \mathrm{kg}$ b.wt CSP p.o, respectively whereas group III animals were administered with silymarin $10 \mathrm{mg} / \mathrm{kg}$ b.wt p.o. for 14 days. All rats were anaesthetized (ISOPLAN ${ }^{\circledR}$ ) and sacrificed after final treatment and blood samples were subsequently obtained for further experiments with dorsal venacava. The liver was extracted from the body of the animals for various investigations.

\subsection{Biochemical Analysis}

Blood samples collected from all groups were centrifuged and serum was assessed for various hepatic enzyme markers like aspartate aminotransferase (AST), alanine transaminase (ALT), alkaline phosphatase (ALP), and total protein TP by following reagent kits manuals.

\subsection{Estimation of Catalase (CAT), Superoxide Dismutase (SOD) and Malondialdehyde (MDA)}

The extracted liver was cleaned and homogenized in chilled buffered saline, the aliquot so obtained was used for the estimation of CAT [58], SOD [59], and MDA [60].

\subsection{Proinflammatory Cytokine Analysis}

Inflammatory mediators TNF- $\alpha$ and COX-2 were evaluated in serum by a commercial diagnostic kit.

\subsection{Histological Evaluation}

The histopathology study was evaluated by the procedure of Tahir et al. [61].

\subsection{Statistical Analysis}

Statistical Package for the Social Sciences (SPSS) Statistics Version 23 was used for the investigation of all the data. Differences among the groups were assessed using the variance analysis taken after by the Tukey-Kramer different comparison test and the least measure for measurable noteworthiness was set at $p<0.05$ for all comparisons.

\subsection{Statement of Ethical Approval}

All procedures for using experimental animals were checked and proper permission was obtained from the Institutes animal ethics committee (Approval No: RAKMHSU-REC-7-2017-F-P). 


\section{Conclusions}

The current study demonstrated that CSP significantly decreased the levels of hepatic enzyme and proinflammatory cytokines markers in the INH-RIF induced rats. The possible bioactive chemical compounds responsible for the hepatoprotective activity of CSP are rutin, morin, festin, and quercetin.

Author Contributions: Conceptualization, A.F.W. and M.U.R.; data curation, A.F.W., M.U.R.; formal analysis, J.R.P., Y.A.D., O.S., S.J., M.R., and B.A.P., A.S.; funding acquisition, A.F.W. and P.A.; investigation, A.F.W., M.U.R., and B.A.P.; methodology, A.F.W., Y.A.D.; project administration, A.F.W., M.U.R., and P.A.; resources, Y.A.D., S.R. and O.S.; software, M.U.R. and S.R.; supervision, M.U.R. and P.A.; validation, A.F.W.; writing-original draft, A.F.W., M.U.R., J.R.P., Y.A.D.; writing-review and editing, M.U.R., B.A.P., and P.A. All authors have read and agreed to the published version of the manuscript.

Funding: This research was funded by RSP-2019/116 and RAKMHSU-REC-7-2017-F-P.

Acknowledgments: The authors would like to present their gratitude to RAK Medical and Health Sciences University for support on this research project RAKMHSU-REC-7-2017-F-P. The authors would like to extend their sincere appreciation to the Researchers Supporting Project Number (RSP-2019/116), King Saud University, Riyadh, Saudi Arabia.

Conflicts of Interest: The authors declare no conflict of interest.

\section{Abbreviations}

\begin{tabular}{|c|c|}
\hline ABTS & (2,2'-azino-bis(3-ethylbenzothiazoline-6-sulfonic acid) \\
\hline ALP & Alkaline phosphatase \\
\hline ALT & Alanine aminotransferase \\
\hline AST & Aspartate aminotransferase \\
\hline ATC & Antituberculosis \\
\hline CAT & Catalase \\
\hline COX-2 & Cyclooxygenase \\
\hline CS & Crocus satious L. \\
\hline CSP & Crocus sativus petals \\
\hline $\mathrm{DIH}$ & Drug-induced hepatotoxicity \\
\hline $\mathrm{DPPH}$ & 2,2-diphenyl-1-picry1hydrazy1 \\
\hline EMB & Ethambutol \\
\hline GAE/g & Gallic acid equivalent per gram \\
\hline IC50 & Half maximal inhibitory concentration \\
\hline ICP-OES & Inductively coupled plasma-optical emission spectrometry \\
\hline INH & Isoniazid \\
\hline LC-ESI-Q-TOFMS & $\begin{array}{l}\text { Liquid chromatography coupled with electrospray ionization-quadrupole-time of } \\
\text { flight-mass spectrometry }\end{array}$ \\
\hline MDA & Malondialdehyde \\
\hline PZA & Pymzinaide \\
\hline $\mathrm{QE} / \mathrm{g}$ & Quercetin equivalent per gram \\
\hline $\mathrm{R} 2$ & Regression \\
\hline RIF & Rifampicin \\
\hline SOD & Superoxide dismutase \\
\hline $\mathrm{TB}$ & Tuberculosis \\
\hline TFC & Total flavonoid content \\
\hline TNF- $\alpha$ & Tumor necrosis factor alpha \\
\hline $\mathrm{TP}$ & Total protein \\
\hline TPC & Total phenolic content \\
\hline $\mathrm{WHO}$ & World Health Organization \\
\hline
\end{tabular}

\section{References}

1. Furin, J.; Cox, H.; Pai, M. Tuberculosis. Lancet 2019, 393, 1642-1656. [CrossRef]

2. Gualano, G.; Capone, S.; Matteelli, A.; Palmieri, F. New antituberculosis drugs: From clinical trial to programmatic use. Infect. Dis. Rep. 2016, 8. [CrossRef] [PubMed] 
3. Zhang, Y. The magic bullets and tuberculosis drug targets. Annu. Rev. Pharmacol. Toxicol. 2005, 45, 529-564. [CrossRef] [PubMed]

4. Hussain, T.; Gupta, R.K.; Sweety, K.; Khan, M.S.; Hussain, M.S.; Arif, M.; Hussain, A.; Faiyazuddin, M.; Rao, C.V. Evaluation of antihepatotoxic potential of Solanum xanthocarpum fruit extract against antitubercular drugs induced hepatopathy in experimental rodents. Asian Pac. J. Trop. Biomed. 2012, 2, 454-460. [CrossRef]

5. Hong, M.; Li, S.; Tan, H.; Wang, N.; Tsao, S.-W.; Feng, Y. Current Status of Herbal Medicines in Chronic Liver Disease Therapy: The Biological Effects, Molecular Targets and Future Prospects. Int. J. Mol. Sci. 2015, 16, 28705-28745. [CrossRef]

6. Sikander, M.; Malik, S.; Parveen, K.; Ahmad, M.; Yadav, D.; Hafeez, Z.B.; Bansal, M. Hepatoprotective effect of Origanum vulgare in Wistar rats against carbon tetrachloride-induced hepatotoxicity. Protoplasma 2012, 250, 483-493. [CrossRef]

7. Rehman, M.U.; Wali, A.F.; Ahmad, A.; Shakeel, S.; Rasool, S.; Ali, R.; Rashid, S.M.; Madkhali, H.; Ganaie, M.A.; Khan, R. Neuroprotective Strategies for Neurological Disorders by Natural Products: An update. Curr. Neuropharmacol. 2019, 17, 247-267. [CrossRef]

8. Moossavi, M.; Hoshyar, R.; Hemmati, M.; Farahi, A.; Javdani, H. An invivo study on the hepato-protective effects of Crocus sativus, Ziziphus jujuba and Berberis vulgaris against acute acetaminophen and rifampicin-induced hepatotoxicity. Clin. Phytoscience 2016, 2. [CrossRef]

9. Alavizadeh, S.H.; Hosseinzadeh, H. Bioactivity assessment and toxicity of crocin: A comprehensive review. Food Chem. Toxicol. 2014, 64, 65-80. [CrossRef]

10. Imenshahidi, M.; Hosseinzadeh, H.; Javadpour, Y. Hypotensive effect of aqueous saffron extract (Crocus sativus L.) and its constituents, safranal and crocin, in normotensive and hypertensive rats. Phytother. Res. 2009. [CrossRef]

11. Nassiri-Asl, M.; Hosseinzadeh, H. Neuropharmacology Effects of Saffron (Crocus sativus) and Its Active Constituents. In Bioactive Nutraceuticals and Dietary Supplements in Neurological and Brain Disease; Elsevier: Amsterdam, The Netherlands, 2015; pp. 29-39. [CrossRef]

12. Mollazadeh, H.; Emami, S.A.; Hosseinzadeh, H. Razi's Al-Hawi and saffron (Crocus sativus): A review. Iran. J. Basic Med. Sci. 2015, 18, 1153. [PubMed]

13. Srivastava, R.; Ahmed, H.; Dixit, R.K.; Saraf, S.A. Crocus sativus L.: A comprehensive review. Pharmacogn. Rev. 2010, 4, 200. [CrossRef] [PubMed]

14. Rahaiee, S.; Moini, S.; Hashemi, M.; Shojaosadati, S.A. Evaluation of antioxidant activities of bioactive compounds and various extracts obtained from saffron (Crocus sativus L.): A review. J. Food Sci. Technol. 2014, 52, 1881-1888. [CrossRef] [PubMed]

15. Yousefsani, B.S.; Pourahmad, J.; Hosseinzadeh, H. The mechanism of protective effect of crocin against liver mitochondrial toxicity caused by arsenic III. Toxicol. Mech. Methods 2017, 28, 105-114. [CrossRef]

16. Zeinali, M.; Zirak, M.R.; Rezaee, S.A.; Karimi, G.; Hosseinzadeh, H. Immunoregulatory and anti-inflammatory properties of Crocus sativus (Saffron) and its main active constituents: A review. Iran. J. Basic Med. Sci. 2019, 22, 334

17. Karimi, E.; Oskoueian, E.; Hendra, R.; Jaafar, H.Z.E. Evaluation of Crocus sativus L. Stigma Phenolic and Flavonoid Compounds and Its Antioxidant Activity. Molecules 2010, 15, 6244-6256. [CrossRef]

18. Bathaie, S.Z.; Mousavi, S.Z. New Applications and Mechanisms of Action of Saffron and its Important Ingredients. Crit. Rev. Food Sci. Nutr. 2010, 50, 761-786. [CrossRef]

19. Khan, N.; Syed, D.N.; Ahmad, N.; Mukhtar, H. Fisetin: A Dietary Antioxidant for Health Promotion. Antioxid. Redox Signal. 2013, 19, 151-162. [CrossRef]

20. Hosseini, A.; Razavi, B.M.; Hosseinzadeh, H. Saffron (Crocus sativus) petal as a new pharmacological target: A review. Iran. J. Basic Med. Sci. 2018, 21, 1091.

21. Kumar, S.; Pandey, A.K. Chemistry and Biological Activities of Flavonoids: An Overview. Sci. World J. 2013, 2013, 1-16. [CrossRef]

22. Nerdy, N.; Ritarwan, K. Hepatoprotective Activity and Nephroprotective Activity of Peel Extract from Three Varieties of the Passion Fruit (Passiflora Sp.) in the Albino Rat. Open Access Maced. J. Med. Sci. 2019, 7, 536-542. [CrossRef] [PubMed]

23. Rehman, M.U.; Ali, N.; Rashid, S.; Jain, T.; Nafees, S.; Tahir, M.; Khan, A.Q.; Lateef, A.; Khan, R.; Hamiza, O.O.; et al. Alleviation of hepatic injury by chrysin in cisplatin administered rats: Probable role of oxidative and inflammatory markers. Pharmacol. Rep. 2014, 66, 1050-1059. [CrossRef] [PubMed] 
24. Jeon, S.H.; Kuppusamy, S.; Yoon, Y.-E.; Kim, H.T.; Lee, Y.B. Are There as Many Essential and Non-essential Minerals in Hydroponic Strawberry (Fragaria ananassa L.) Compared to Those Grown in Soil? Biol. Trace Elem. Res. 2018, 187, 562-567. [CrossRef] [PubMed]

25. Wali, A.F.; Avula, B.; Ali, Z.; Khan, I.A.; Mushtaq, A.; Rehman, M.U.; Akbar, S.; Masoodi, M.H. Antioxidant, Hepatoprotective Potential and Chemical Profiling of Propolis Ethanolic Extract from Kashmir Himalaya Region Using UHPLC-DAD-QToF-MS. BioMed. Res. Int. 2015, 2015, 1-10. [CrossRef]

26. Ranawat, L.; Bhatt, J.; Patel, J. Hepatoprotective activity of ethanolic extracts of bark of Zanthoxylum armatum DC in CCl4 induced hepatic damage in rats. J. Ethnopharmacol. 2010, 127, 777-780. [CrossRef]

27. Soetan, K.; Olaiya, C.; Oyewole, O. The importance of mineral elements for humans, domestic animals and plants-A review. Afr. J. Food Sci. 2010, 4, 200-222.

28. Huang, D.; Ou, B.; Prior, R.L. The Chemistry behind Antioxidant Capacity Assays. J. Agric. Food Chem. 2005, 53, 1841-1856. [CrossRef]

29. Mujahid, M.; Siddiqui, H.H.; Hussain, A.; Hussain, M.S. Hepatoprotective effects of Adenanthera pavonina (Linn.) against anti-tubercular drugs-induced hepatotoxicity in rats. Pharmacogn. J. 2013, 5, 286-290. [CrossRef]

30. Santhosh, S.; Sini, T.K.; Anandan, R.; Mathew, P.T. Effect of chitosan supplementation on antitubercular drugs-induced hepatotoxicity in rats. Toxicology 2006, 219, 53-59. [CrossRef]

31. Lynch, T.; Price, A. The effect of cytochrome P450 metabolism on drug response, interactions, and adverse effects. Am. Fam. Physician 2007, 76, 391-396.

32. Metushi, I.; Uetrecht, J.; Phillips, E. Mechanism of isoniazid-induced hepatotoxicity: Then and now. Br. J. Clin. Pharmacol. 2016, 81, 1030-1036. [CrossRef] [PubMed]

33. Tasduq, S.A.; Peerzada, K.; Koul, S.; Bhat, R.; Johri, R.K. Biochemical manifestations of anti-tuberculosis drugs induced hepatotoxicity and the effect of silymarin. Hepatol. Res. 2005, 31, 132-135. [CrossRef] [PubMed]

34. Wang, P.; Pradhan, K.; Zhong, X.-B.; Ma, X. Isoniazid metabolism and hepatotoxicity. Acta Pharm. Sin. B 2016, 6, 384-392. [CrossRef] [PubMed]

35. Pauli-Magnus, C.; Meier, P.J. Hepatobiliary transporters and drug-induced cholestasis. Hepatology 2006, 44, 778-787. [CrossRef] [PubMed]

36. Omidi, A.; Riahinia, N.; Torbati, M.B.M.; Behdani, M.-A. Hepatoprotective effect of Crocus sativus (saffron) petals extract against acetaminophen toxicity in male Wistar rats. Avicenna J. Phytomedicine 2014, 4, 330.

37. Miltonprabu, S.; Tomczyk, M.; Skalicka-Woźniak, K.; Rastrelli, L.; Daglia, M.; Nabavi, S.F.; Alavian, S.M.; Nabavi, S.M. Hepatoprotective effect of quercetin: From chemistry to medicine. Food Chem. Toxicol. 2017, 108, 365-374. [CrossRef]

38. Rizvi, F.; Mathur, A.; Kakkar, P. Morin mitigates acetaminophen-induced liver injury by potentiating Nrf2 regulated survival mechanism through molecular intervention in PHLPP2-Akt-Gsk3 $\beta$ axis. Apoptosis 2015, 20, 1296-1306. [CrossRef]

39. Bansal, A.K.; Bansal, M.; Soni, G.; Bhatnagar, D. Protective role of Vitamin E pre-treatment on N-nitrosodiethylamine induced oxidative stress in rat liver. Chem. -Biol. Interact. 2005, 156, 101-111. [CrossRef]

40. Kurutas, E.B. The importance of antioxidants which play the role in cellular response against oxidative/nitrosative stress: Current state. Nutr. J. 2015, 15. [CrossRef]

41. Pham-Huy, L.A.; He, H.; Pham-Huy, C. Free radicals, antioxidants in disease and health. Int. J. Biomed. Sci. IJBS 2008, 4, 89 .

42. Tao, L.; Qu, X.; Zhang, Y.; Song, Y.; Zhang, S.-X. Prophylactic Therapy of Silymarin (Milk Thistle) on Antituberculosis Drug-Induced Liver Injury: A Meta-Analysis of Randomized Controlled Trials. Can. J. Gastroenterol. Hepatol. 2019, 2019, 1-11. [CrossRef] [PubMed]

43. Zhu, R.; Wang, Y.; Zhang, L.; Guo, Q. Oxidative stress and liver disease. Hepatol. Res. 2012, 42, 741-749. [CrossRef] [PubMed]

44. Lykkesfeldt, J. Malondialdehyde as biomarker of oxidative damage to lipids caused by smoking. Clin. Chim. Acta 2007, 380, 50-58. [CrossRef] [PubMed]

45. Muriel, P. Role of free radicals in liver diseases. Hepatol. Int. 2009, 3, 526-536. [CrossRef] [PubMed]

46. Slater, T.F. Free-radical mechanisms in tissue injury. Biochem. J. 1984, 222, 1-15. [CrossRef] [PubMed] 
47. Kandimalla, R.; Kalita, S.; Choudhury, B.; Devi, D.; Kalita, D.; Kalita, K.; Dash, S.; Kotoky, J. Fiber from ramie plant (Boehmeria nivea): A novel suture biomaterial. Mater. Sci. Eng. C 2016, 62, 816-822. [CrossRef] [PubMed]

48. Luckey, S.W.; Petersen, D.R. Activation of Kupffer Cells During the Course of Carbon Tetrachloride-Induced Liver Injury and Fibrosis in Rats. Exp. Mol. Pathol. 2001, 71, 226-240. [CrossRef] [PubMed]

49. Nguyen-Lefebvre, A.T.; Horuzsko, A. Kupffer cell metabolism and function. J. Enzymol. Metab. $2015,1,1$.

50. Sun, X.-F.; Zhang, H. NFKB and NFKBI polymorphisms in relation to susceptibility of tumour and other diseases. Histol. Histopathol. 2007, 12, 1387-1398.

51. Zhang, H.Y.; Wang, H.L.; Zhong, G.Y.; Zhu, J.X. Molecular mechanism and research progress on pharmacology of traditional Chinese medicine in liver injury. Pharm. Biol. 2018, 56, 594-611. [CrossRef]

52. Babaei, A.; Arshami, J.; Haghparast, A.; Mesgaran, M.D. Effects of saffron (Crocus sativus) petal ethanolic extract on hematology, antibody response, and spleen histology in rats. Avicenna J. Phytomedicine 2014, 4, 103.

53. Nazima, B.; Manoharan, V.; Miltonprabu, S. Grape seed proanthocyanidins ameliorates cadmium-induced renal injury and oxidative stress in experimental rats through the up-regulation of nuclear related factor 2 and antioxidant responsive elements. Biochem. Cell Biol. 2015, 93, 210-226. [CrossRef] [PubMed]

54. Domitrović, R.; Jakovac, H.; Vasiljev Marchesi, V.; Vladimir-Knežević, S.; Cvijanović, O.; Tadić, Ž.; Romić, Ž.; Rahelić, D. Differential hepatoprotective mechanisms of rutin and quercetin in CCl4-intoxicated BALB/cN mice. Acta Pharmacol. Sin. 2012, 33, 1260-1270. [CrossRef] [PubMed]

55. Ayoub, N.; Nematallah, K.A.; Al-Gendy, A.A.; Zaghloul, S.S. Novel quercetin glycoside with promising hepatoprotective activity isolated from Lobularia libyca (viv). CfW (Brassicaceae). Eur. Sci. J. 2013, 9, 21.

56. Chang, C.-C.; Yang, M.-H.; Wen, H.-M.; Chern, J.-C. Estimation of total flavonoid content in propolis by two complementary colorimetric methods. J. Food Drug Anal. 2002, 10, 3.

57. Ullah, F.; Ayaz, M.; Sadiq, A.; Hussain, A.; Ahmad, S.; Imran, M.; Zeb, A. Phenolic, flavonoid contents, anticholinesterase and antioxidant evaluation of Iris germanica var;florentina. Nat. Prod. Res. 2015, 30, 1440-1444. [CrossRef]

58. Claiborne, A. Catalase activity. In CRC Handbook of Methods for Oxygen Radical Research; CRC Press: Boca Raton, FL, USA, 1985; pp. 283-284.

59. Marklund, S.; Marklund, G. Involvement of the superoxide anion radical in the autoxidation of pyrogallol and a convenient assay for superoxide dismutase. Eur. J. Biochem. 1974, 47, 469-474. [CrossRef]

60. D'souza, D.; Babu, G.; Shetty, S.; Balan, P. Estimation of serum malondialdehyde in potentially malignant disorders and post-antioxidant treated patients: A biochemical study. Contemp. Clin. Dent. 2012, 3, 448. [CrossRef]

61. Tahir, M.; Rehman, M.U.; Lateef, A.; Khan, R.; Khan, A.Q.; Qamar, W.; Ali, F.; O'Hamiza, O.; Sultana, S. Diosmin protects against ethanol-induced hepatic injury via alleviation of inflammation and regulation of TNF- $\alpha$ and NF-kB activation. Alcohol 2013, 47, 131-139. [CrossRef]

(C) 2020 by the authors. Licensee MDPI, Basel, Switzerland. This article is an open access article distributed under the terms and conditions of the Creative Commons Attribution (CC BY) license (http://creativecommons.org/licenses/by/4.0/). 